\title{
Risk identification and prioritization in banking projects of payment service provider companies: an empirical study
}

\author{
Mohammad Khalilzadeh ${ }^{1,2^{*}}$ (D) Laleh Katoueizadeh ${ }^{3}$ and Edmundas Kazimieras Zavadskas ${ }^{4}$
}

\author{
* Correspondence: khalilzadeh@ \\ pucp.edu.pe \\ ${ }^{1}$ CENTRUM Católica Graduate \\ Business School, Lima, Peru \\ ${ }^{2}$ Pontificia Universidad Católica del \\ Perú, Lima, Peru \\ Full list of author information is \\ available at the end of the article
}

\begin{abstract}
Identifying risks and prioritizing is important for payment service provider (PSP) companies to get banking projects and gain more market share. However, studies regarding the identification of risks and causal relationships are insufficient in the Iranian PSP industry and the industry is unique because of its characteristics. In this study, 30 experts involved with PSP companies are employed as the research sample. Eleven key risks and Forty-six sub-risks are also identified. Subsequently, the fuzzy decision-making trial and evaluation laboratory technique is applied to determine the effective and affected risks and the severity of their effects on each other. Finally, all risks are ranked. Due to the internal interrelationships of the main risks, the weight of each risk is calculated via the fuzzy analytic network process. As the second-level risks have no significant interrelationships, they are ranked via the fuzzy analytical hierarchy process. Moreover, the best-worst method is used to ensure that the obtained rankings are reliable. This study identifies the risks affecting the loss of banking projects and determines the impacts of these risks on each. A sensitivity analysis is then conducted on the weights of the criteria, and the results are compared.
\end{abstract}

Keywords: Payment service provider (PSP), Risk identification, Risk assessment, Fuzzy decision-making trial and evaluation laboratory (DEMATEL), Fuzzy analytic network process (ANP), Best-worst method (BWM), Prioriation

\section{Introduction}

Globalization has influenced the technological transformation, customer expectations, Internet use, E-commerce, and the intensity and diversity of competition among organizations. Currently, electronic banking is ubiquitous. The speed of transformation in the business world is increasing, and banks continue to seek innovative services for their customers. Major financial firms such as payment service provider (PSP) companies in Iran mediate between banks and their customers, and provide more convenient payment services for the public. Banking payment services facilitate payment operations for various businesses via channels such as Internet payment gateways and payment applications. Such services are provided by PSP companies to facilitate the payment of services or goods without using bank notes.

(c) The Author(s). 2020 Open Access This article is licensed under a Creative Commons Attribution 4.0 International License, which permits use, sharing, adaptation, distribution and reproduction in any medium or format, as long as you give appropriate credit to the original author(s) and the source, provide a link to the Creative Commons licence, and indicate if changes were made. The images or other third party material in this article are included in the article's Creative Commons licence, unless indicated otherwise in a credit line to the material. If material is not included in the article's Creative Commons licence and your intended use is not permitted by statutory regulation or exceeds the permitted use, you will need to obtain permission directly from the copyright holder. To view a copy of this licence, visit http://creativecommons.org/licenses/by/4.0/. 
In the wake of the public's acceptance of new payment tools, banks have also realized the importance of attracting funds and the turnover created by the non-use of cash; thus, they aim to increase their activity in this area. E-banking today is indispensable. The expansion and promotion of electronic payment require the installation, commissioning, testing, and maintenance of point of sale (POS) terminals, as well as the launch of software for Internet and mobile payments. According to the E-money Act in Iran, banks can delegate the task of providing payment services to PSPs (licensed by the Central Bank of the Islamic Republic of Iran) via contracts.

Currently, 12 PSP companies are eligible to provide services for banks in Iran. Since banks are considered as the customers of PSPs, these companies intensely compete to keep customers and gain more market share. PSPs that can better identify and respond to the needs and desires of their clients can retain and grow further in this industry since two main challenges for these companies are the loss of contracts with banks and M\&A by rival companies.

Project risk management primarily identifies, assesses, and controls the risks of projects. Moreover, due to the existence of different stakeholders with varying criteria for assessing the success of the project, measuring the success of the project is challenging. Identifying risks as the first step in the risk management is essential for the successful implementation of projects. In the second step, the identified risks associated with PSPs' banking projects are assessed and prioritized. Identifying and prioritizing these risks will significantly help PSPs to identify key risk factors and prioritize them to satisfy their current customers and sign new contracts with new banks. This study employs the Delphi method for the risk identification process; the risks affecting the loss of banking projects in PSPs are identified, and the impacts of these risks on each other are determined.

One of the decision-making tools to identify and prioritize the impacts of risks on each other is the combination of the decision-making trial and evaluation laboratory (DEMATEL) and fuzzy analytic network process (ANP). Moreover, the best-worst method (BWM) is beneficial for determining the weight of each risk. The appropriateness of these approaches for prioritizing risks is mentioned in previous studies. However, since this industry is emerging, these risks have not been identified and assessed in Iranian PSP companies. The outcomes of this research are based on the prioritization and importance of the known risks in this industry. Since this industry is rapidly advancing, the risks vary continuously. Therefore, the ranks are not constant. This study helps managers identify risks and provides scope for future research.

\section{Literature review}

\section{Project risk management}

Project risk management is conducted to identify and analyze risks for easy comprehension and effective management (Mojtahedi et al. 2010). All projects are subjected to potential risks. Project risk management is responsible for responding appropriately to project risks (Marchewka 2009). Project risks should be identified and evaluated based on the probability of occurrence and their potential impacts on the project (Cooper et al. 2005).

There are various techniques for identifying project risks, and no unique solution qualifies as the best identification method (Kasap and Kaymak 2007). Information 
collection techniques for risk identification include mental storms, Delphi, interviews, and analysis of Strengths, Weaknesses, Opportunities, and Threats (SWOT) (Rose 2013).

For general risk management, Jiang et al. (2009), in their study in China, stated that electronic intermediaries are one of the most important business models in the Internet era. They found that consumer trust was influenced by three factors: brand credibility, perceived technology acceptance, and individual consumer differences. Hui et al. (2008) identified the risks in the internationalization of Chinese hi-tech companies by integrating Miller's international risk theory with Johanson's progressive internationalization theory. They formed the combined model of internationalization entry-degree and integrated risk perception.

$\mathrm{Xu}$ et al. (2011) showed that host country risk, as well as cultural distance, have significant effects on the entry mode choices of Chinese enterprises.

Diao and Ghorbani (2018) identified a variety of production risks and human factors that positively or negatively affect production. They also distinguished useful methods to tackle identified human factors, thus highlighting working attitude, safety awareness, creativity, and environmental protection awareness, which affects production risks in thermal power plants.

As for risk identification and management of PSP companies, Park et al. (2019) investigated mobile payment services and examined the relationship between risk, profit, and trust in accepting mobile PSP services according to effects of demographic factors, such as income, age, and education.

To protect consumers' financial transactions, PSP companies should develop security programs to increase consumer confidence in using these services, which, in turn, increases the interest and engagement of other consumers (Heitz-Spahn 2013).

Reducing uncertainties regarding beliefs and environments increases trust in technology and service providers. To get started on using PSP mobile services, consumers must first open an account with PSPs. Second, customers must send payment requests and make transactions. The final step is the settlement (Nambiar and Lu 2005). Risk can occur in any of the above steps, such as unauthorized transactions, transaction errors, inadequate records and transaction documents, transaction uncertainty, privacy issues, and problems in mobile or device network reliability (Bauer et al. 2005). By reducing these risks, PSPs can increase consumer confidence (Wachinger et al. 2013; Zhou 2013).

Kim et al. (2008) stated that if the risks are high, understanding that the potential benefits outweigh the risks can motivate consumers. Therefore, risk recognition is one of the most important factors in dealing with online and mobile payments (Slade et al. 2015).

PSP service companies should evaluate payment plans and assess the risks associated with payment services in payment plans and they must be updated regularly. Regular risk assessment makes sense in the light of rapid technological advances and the fact that fraudsters have become more organized and their attacks, more sophisticated (Kovacs and David 2016).

PSPs must evaluate the adequacy of their internal security controls against internal and external risk scenarios. These controls should cover all processing, control, and payment process, including access to payment services, and monitoring and authorization. The first recommendation can be divided into five general control and security actions (i.e., government matters, risk identification and assessment, monitoring and reporting, risk control and reduction, and traceability). The second recommendation includes specific control 
and security actions for payment services (including customer identification and basic information, customer authentication, customer registration, registration to provide client or software authentication tools, login attempts, validation, monitoring, and protection of sensitive payment data). The third recommendation is customer education and communication (including notification, limitation, and customer access to payment status information) (Kovacs and David 2016).

\section{Application of decision-making models in risk management}

Decision-making models have been used in many studies in the field of risk, some of which are presented in Table 1 . The novelty of this study regards the identification of risks in the PSP industry.

Risk management is essential in projects. As management process must be conducted empirically and systematically, one of the risk management stages that has been emphasized by many researchers is the assessment and analysis of risk factors regarding project goals. After identifying risk factors in projects by means of the DEMATEL-ANP technique in the PSP industry, it is implied that the financial and external risks, as well as the contractual and operational risks, have the highest impact. The results are also applied in industrial models. The fuzzy theory is used to reduce the mistakes of experts (Soofifard et al. 2017).

According to Chen et al. (2016), reducing project risks of information systems and improving organizational performance has become an important research concern. The research outline of their study is constructed from the Stimulus Organism Response (SOR) framework based on related studies, which is comprised of the stimulus of the project risk, the organism of project management, and the response of organizational performance. DEMATEL-based ANP (DANP) is used as a decision-making tool for analysis. The results revealed that effective project management reduces project risk and enhances organizational performance. Moreover, organizational environment risk is the most challenging among all types of project risks. Supporting senior managers is crucial in project management, and the multi-dimensional aspects of an organizational performance have received equal attention, thus indicating that financial performance is not the only essential object (Chen et al. 2016).

Table 1 The brief review of the application of DEMATEL-ANP and BWM techniques in risk management

\begin{tabular}{lll}
\hline Literature & Subject & Methodology \\
\hline Nazeri and Naderikia (2017) & $\begin{array}{l}\text { Identification of the critical risk factors in } \\
\text { maintenance management }\end{array}$ & DEMATEL-ANP \\
Fazli et al. (2015) & Crude oil supply chain risk management & DEMATEL-ANP \\
Zhou et al. (2014) & $\begin{array}{l}\text { Safety assessment of high-risk hydropower- } \\
\text { construction-project work system }\end{array}$ & DEMATEL-ANP \\
Ouyang et al. (2013) & Information security risk control assessment & DEMATEL-ANP \\
Tsai et al. (2013) & Information technology auditing and risk control & DEMATEL-ANP \\
in resource planning & BWh \\
Torabi et al. (2016) & Appraisal of humanitarian supply chain risks & BWM \\
\end{tabular}


Dehdasht et al. (2017) recognized the dimensions and variables of critical risk factors that can have a significant effect on risk management in oil and gas companies (OGC). Following the DEMATEL analysis, the interdependencies among risk groups were evaluated to improve decision-making in OGC projects. The results showed that "financial" and "technical" dimensions are the most important due to their interrelationships with other dimensions. Accordingly, it could be concluded that "environmental" risk factors are critical for the successful execution of risk management in OGC projects due to their effect on other factors. Furthermore, improving other risk factors without attending to the risk factors classified in the environmental dimension cannot lead to a desirable result. Moreover, due to the obtained weighting of the critical risk factors in OGC projects by the ANP model, it was concluded that "contractual" and "design and construction" are the most affecting risk factors. Thus, it was found that the "lack of financial supports for projects," "errors in designing," "delay in auditing and monthly contract payment," and "poor quality of purchased material or material loss" are essential risk factors in OGC projects. Hence, these risk factors require more attention for a successful risk management (Dehdasht et al. 2017).

The crude oil supply chain is extremely complex and vulnerable to various risks. A delicate understanding of the probable risks can help managers make effective decisions. Thus, to identify the main risks related to the crude oil supply chain and determine the interdependency between risks, the best response strategy is determined via an DEMATEL-ANP model. First, the DEMATEL method is implemented to determine the interdependency between risks. The ANP method is then applied to evaluate the importance of each risk. The results revealed that the most important risk area is regulatory and environmental risks. Moreover, cooperation policy is regarded as the best response strategy (Fazli et al. 2015).

Planning to respond to the risks is important for project managers to control different risks. After evaluating project risks, the final procedure is to choose a desirable response to the risk. Hence, a comprehensive framework is defined in three main phases. First, all the risks, responses, and their relations in a geothermal drilling project are detected. The relations imply that there are inner and outer dependent relations. Then, risks and responses are weighted via DEMATEL-ANP methods. Finally, a more realistic solution is enabled by a zero-one integer programming, which reflects a budget and other required constraints (Ghassemi and Darvishpour 2018).

Repair and maintenance are conducted to prevent the events leading to a malfunction and disruption of the production process or the operation of the concerned equipment. Finding the risk of equipment failure mode is one of the main methodologies in maintenance. Moreover, by reducing the high risk of failure mode, the reliability of the equipment is enhanced, and the closure cost is reduced. Thus, to select an appropriate maintenance policy, a fuzzy hybrid approach is employed, including failure mode and effects analysis (FMEA), DEMATEL, and ANP. The weight of risk factors, failure occurrence, failure severity, and failure detection are considered in the FMEA. The DEMATEL method is then used to consider the interrelationship among the main risks which were determined via the fuzzy FMEA. Formerly, the weights of the sub-risks are measured by the fuzzy ANP approach. According to a case study carried out in the repair and maintenance of the Iranian Railways Co., the failures recorded in a computerized maintenance management system (CMMS) were first categorized and evaluated by 
experts. The relationships between the risks and sub-risks and their weights were then determined. The final weights of the risks and sub-risks were obtained by increasing the risk priority number (RPN) via the FMEA, and six critical hazards were defined. Engine risk, pneumatic risk, and transmission risk were the most important risks. Therefore, based on the obtained weights, these risks were prioritized (Nazeri and Naderikia 2017).

In a study on hydropower-construction-project management, safety management risks in the work system and the relationships of the risks in this area were calculated via DEMATEL, and their weights were calculated using the ANP model. The results revealed that the most important identified factors for safety management of these projects are monitoring and safety inspection, as well as organization and responsibility (Zhou et al. 2014). Recently, an increase in artificial and natural disasters severely impacted human lives. Hence, one of the important issues in human chain management is to identify and prioritize different risks and find suitable solutions. In a case study in the Tehran Red Crescent Societies, after identifying risks using the BWM, the importance of each was examined. The outcomes showed that cultural contexts, poor awareness, and poor education system were the most important humanitarian supply chain risks (Mohaghar et al. 2017). Each organization is exposed to numerous risks. The business continuity management system (BCMS) is one of the most recent and effective risk management frameworks, which supports organizations in enhancing their resilience to cope with the identified risks. Risk assessment is a major part of the BCMS. Moreover, the results of applying the proposed framework in a real-world case study for evaluating the risks obtained by the BWM, demonstrate that it can effectively handle risk assessment and management process when implementing BCMS in an organization (Torabi et al. 2016).

\section{Research methodology}

This study primarily identifies and evaluates risks to improve the services of PSPs. Therefore, this research falls into the category of applied research (regarding purpose and orientation) and a descriptive survey (regarding the method of collecting data). Project risk management is primarily conducted to identify, assess, and control project risks. Measuring the success of the project is challenging due to different stakeholder criteria. The identification of risks is surely the first step in the process of risk management. This study employs the Delphi method to identify risks. Given the subject matter of the research, the target population includes senior executives, project managers, and experts involved in PSP companies. A sample of 30 experts was selected to identify and prioritize risks and prepare the required reports. Electronic payment service systems are inherently complex; they incorporate a set of interdependent elements (the performance of the representative offices affects corporate reputation and customer retention; consequently, customer retention enhances corporate credibility). Thus, a model that cannot consider these relationships is not ideal for analysis. DEMATEL is among the best decision-making methods that illustrate the causal relationships of factors; it identifies the affecting and affected risks and the severity of their effects on each other. Thus, to implement this technique in the first stage, the severity of the effects of the risks on each other has been determined by using the pairwise comparison questionnaire. Moreover, the average expert opinion is considered as the input of the DEMATEL technique. The DEMATEL method is used to quantify and prioritize the 
relationships among the factors, which allows for a clear representation of the relationships within the system (Chauhan et al. 2016; Reyes et al. 2011; Wang et al. 2018). Therefore, the output of this technique is illustrated as the causal relationships among risks. The causal relationship network derived from the DEMATEL method was considered as the input of the fuzzy ANP technique, which was selected to identify the priority of risk. Notably, the weights of the respective risks was calculated via the fuzzy ANP technique. A sensitivity analysis was performed on the weights of the criteria, and the respective results were compared. Since the identified sub-risks had no significant effect on each other, the fuzzy analytic hierarchy process (AHP) method was employed to identify their weights. The BWM method was also employed to ensure that the main risks were ranked according to similar results. Analyzing the results of the above decision-making techniques resulted in the identification of risk causal relationships and, ultimately, the prioritization of risks and sub-risks. Figure 1 illustrates the conceptual model of the research.

\section{Delphi technique}

The Delphi technique is employed to obtain consensus via a series of questionnaires and provide feedback in key areas. The theoretical framework presented in Fig. 2 clearly illustrates the principles behind the Delphi technique in qualitative research (Habibi et al. 2014). With the Delphi method, expert views are collected by a coordinator. The coordinator then provides a summary of the results for other experts, after which the views are refined based on the summary of the previous results. Finally, after reaching a consensus, the results are presented in the form of a report for decision making (Antcliff et al. 2013; Cowan et al. 2015; von der Gracht 2012).

\section{Fuzzy DEMATEL technique}

DEMATEL is a comprehensive method for designing and analyzing models with complex causal relationships among factors. The graph-based observational method provides visual programming and problem-solving such that related factors can be categorized as cause and effect, which renders the relationships to be better understood. DEMATEL's final product is a visual map showing the relationships between factors to help managers solve the problem (Vujanović et al. 2012). The DEMATEL model is based on a pairwise comparison that utilizes expert opinions on the extraction of factors. The systematic structuring and application of the principles of graph theory to provide the hierarchical structure of existing factors, along with the mutual effect of the factors is quantitatively determined (Patil and Kant 2014). The fuzzy DEMATEL technique makes decision-making easy in an uncertain environment with fuzzy linguistic variables (Zhou et al. 2011).

The steps of the fuzzy DEMATEL method are as follows:

\section{Step 1. Determining the criteria (factors) and designing the fuzzy linguistic scale}

At this stage, it is necessary to set criteria for evaluation. The fuzzy linguistic scale is then determined in the evaluation of the direct impact of each factor on the other factors. Table 2 presents the triangular fuzzy numbers and the fuzzy linguistic scale. 


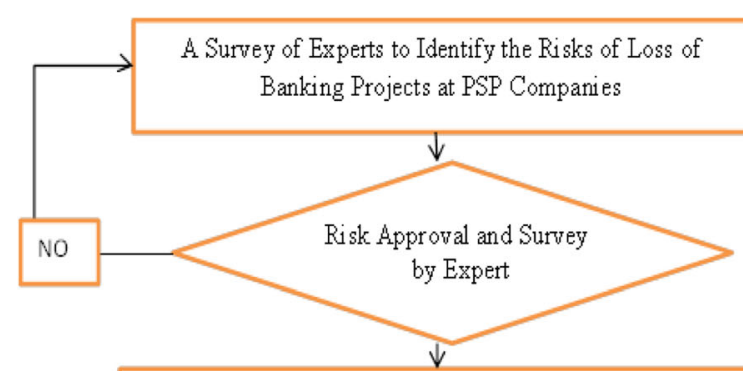

Performing pairwise comparison of the main factors

Identification of the interactions of the main factors on each other using the fuzzy dimetallic method

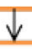

Identification of the interactions of the main factors on each other using the fuzzy DEMATEL method Identification of the interactions of the main factors on each other using the fuzzy dimetallic method

Formation of the network of causal agents relations based on the output of the fuzzy DEMATEL method

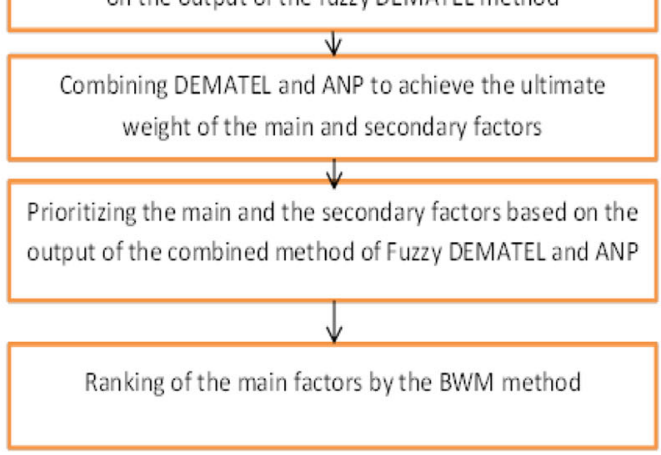

Fig. 1 The conceptual model of the research

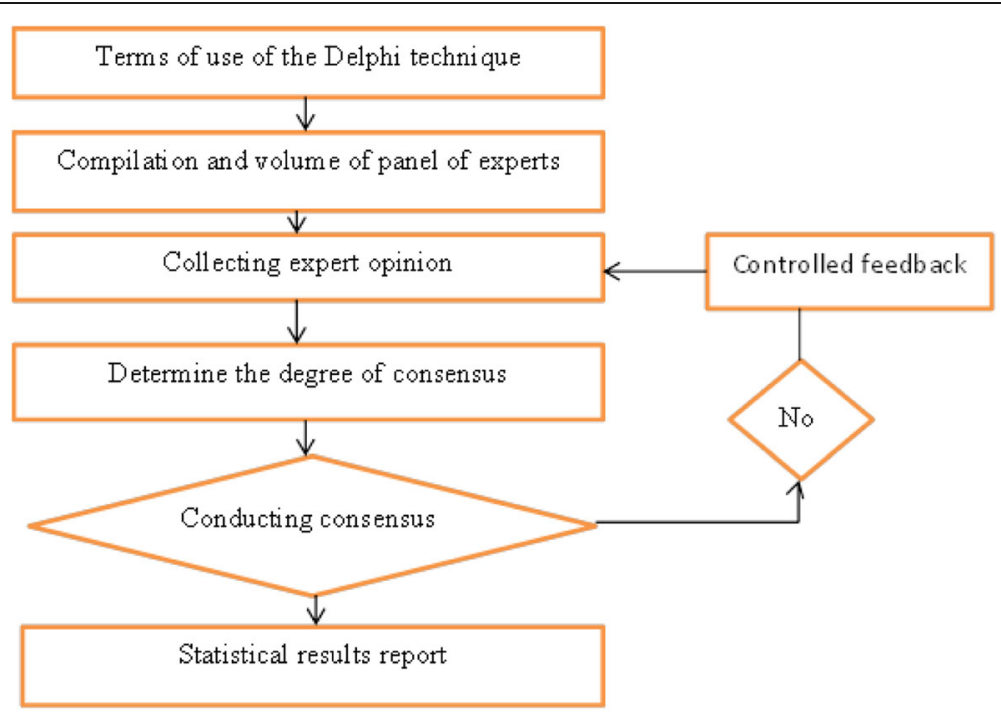

Fig. 2 The theoretical framework of the Delphi technique in qualitative research 
Table 2 Linguistic variables and their equivalent fuzzy numbers

\begin{tabular}{lll}
\hline Linguistic expressions & Numerical values & Triangular fuzzy numbers \\
\hline Extremely high impact $(\mathrm{VH})$ & 4 & $(0.75,1,1)$ \\
High impact $(\mathrm{H})$ & 3 & $(0.5,0.75,1)$ \\
Low impact $(\mathrm{I})$ & 2 & $(0.25,0.5,0.75)$ \\
Very low impact $(\mathrm{VL})$ & 1 & $(0,0.25,0.5)$ \\
No impact $(\mathrm{N})$ & 1 & $(0,0,0.25)$ \\
\hline
\end{tabular}

Source: Lee et al. 2011; Potdar et al. 2017

\section{Step 2. Formation of the direct relationship matrix}

At this stage, the direct impact between the criteria is conducted with the help of experts via the 5-level comparison scale (Table 2). In these matrices, $\tilde{z}_{i j}=\left(l_{i j}, m_{i j}, u_{i j}\right)$ are triangular fuzzy numbers and $\tilde{z}_{i i}=i=1,2,3, \ldots, n$ are the fuzzy number of $(0,0,0)$ (Yeh and Huang 2014). Moreover, a set of pairwise comparisons is obtained from expert opinions regarding linguistic terms. If a decision-making group, including $P$ experts, has been questioned, the number $P$ of the fuzzy matrix will be obtained by using any expert opinion. $P$ is the matrix of the direct fuzzy relationship of each expert. After summing up the experts via Eq. (1), their arithmetic average is calculated via the matrix of the direct fuzzy relation $z$, obtained from the matrices $\tilde{z}^{1}$ ، $\tilde{z}^{2}$ ‘... $\tilde{z}^{p}$ (Uygun et al. 2015).

$$
\tilde{z}=\frac{\tilde{z}^{1} \oplus \tilde{z}^{2} \oplus \tilde{z}^{3} \oplus \ldots \oplus \tilde{z}^{P}}{P}
$$

where $P$ is the number of experts and $\tilde{z}^{1}, \tilde{z}^{2}, \tilde{z}^{P}$ are the pairwise comparison matrices of experts 1,2 , and $P$, respectively.

\section{Step 3. Normalizing the direct relationship matrix}

Eqs. (2) and (3) are used to normalize the obtained matrix.

$$
\tilde{H}_{i j}=\frac{\tilde{z}_{i j}}{r}=\left(\frac{l_{i j}}{r}, \frac{m_{i j}}{r}, \frac{u_{i j}}{r}\right),
$$

where $r$ is obtained via the following equation:

$$
r=\max _{1 \leq i \leq n}\left(\sum_{j=1}^{n} u_{i j}\right) .
$$

\section{Step 4. Calculating the fuzzy general relationship matrix}

After calculating the above matrices, the matrix of total fuzzy relationships is obtained via Eqs. (4) to (7).

In these equations, $I$ is the identity matrix, and $H_{b} H_{m}$, and $H_{u}$ are $n \times n$ matrices, in which, the elements contain the lower number, the middle number, and the upper number of the triangular fuzzy numbers of the matrix $\tilde{T}$, respectively (Uygun et al. 2015). 


$$
\begin{gathered}
T=\lim _{k \rightarrow+\infty}\left(\tilde{H}^{1} \oplus \tilde{H}^{2} \oplus \ldots \oplus \tilde{H}^{k}\right), \\
\tilde{t}_{i j}=\left(l_{i j}^{t}, m_{i j}^{t}, u_{i j}^{t}\right), \\
{\left[l_{i j}^{t}\right]=H_{l} \times\left(I-H_{l}\right)^{-1},} \\
{\left[m_{i j}^{t}\right]=H_{m} \times\left(I-H_{m}\right)^{-1},} \\
{\left[u_{i j}^{t}\right]=H_{u} \times\left(I-H_{u}\right)^{-1} .}
\end{gathered}
$$

\section{Step 5. Defuzzifying}

Eq. (8) is used for defuzzification. The resulting matrix is the $T$ matrix (Özdemir and Tüysüz 2017; Patil and Kant 2014; Yeh and Huang 2014).

$$
d F_{i j}=\frac{\left[\left(r_{i j}-l_{i j}\right)+\left(m_{i j}-l_{i j}\right)\right]}{3}+l_{i j}
$$

\section{Step 6. Drawing the casual chart}

The next step is to calculate the sum of the rows and columns of the matrix $\tilde{T}$, given by Eqs. (9) and (10).

$$
\begin{aligned}
& \tilde{D}=\left(\tilde{D}_{i}\right)_{n \times 1}=\left[\sum_{j=1}^{n} \tilde{T}_{i j}\right]_{n \times 1}, \\
& \tilde{R}=\left(\tilde{R}_{i}\right)_{1 \times n}=\left[\sum_{j=1}^{n} \tilde{T}_{i j}\right]_{1 \times n},
\end{aligned}
$$

where $\tilde{D}$ and $\tilde{R}$ are $n \times 1$ and $1 \times n$ matrices, respectively.

After the defuzzification, the effectiveness and susceptibility intensity graphs are plotted to form the basis of decision-making. $(\tilde{D}+\tilde{R})$ is on the horizontal axis and $(\tilde{D}-\tilde{R})$ is on the vertical axis. The values $(\tilde{D}+\tilde{R})$ show the importance of each factor. Moreover, the higher the value of this factor, the more important it is. $(\tilde{D}-\tilde{R})$ on the vertical axis, divides the factors into two causative groups. If $(\tilde{D}-\tilde{R})$ is positive, then the agent is the cause; if negative, it belongs to the effect group (Shieh et al. 2010).

\section{Fuzzy AHP technique}

The AHP technique is a well-known multi-dimensional decision-making technique, developed by Thomas L. Saaty. In this method, the decision-maker starts by providing a decision hierarchy tree. This tree shows the indicators and decision options. A pair of comparisons is then conducted. These comparisons determine the weight of each of the factors in line with rival options. Finally, the AHP logic integrates the matrices derived from the pairwise comparison such that it provides an optimal decision 
(Ghandehary et al. 2014). The basic assumption of the AHP method is the independence of the sub-criteria or criteria (Saaty and Vargas 2006). A good decision-making model should be effective in ambiguous and inaccurate situations since ambiguity is the common property of many decision-making problems (Yu 2002). In response to this need, the AHP has been used by different authors regarding the fuzzy environment. Chang (1996) introduced triangular fuzzy numbers to use in the fuzzy AHP method. Further, the concepts of the fuzzy AHP are described based on the extent analysis (EA) method. Thus, to simplify the AHP implementation method, instead of using the super-matrix idea provided by Saaty, this study employs the matrix computations in the EA method as its basis (Saaty and Takizawa 1986). The procedure is as follows. Without considering the relationship between the criteria, the experts were asked to evaluate the criteria based on pairwise comparisons. They answered questions such as the following. Which measure has more impact than the others, and to what extent? Triangular fuzzy numbers were employed to complete the pairwise comparison. The geometric meanings of the expert opinions were then prepared for subsequent calculations. The pairwise comparison matrix represents the expert opinion, and fuzzy numbers adequately unite the scattered views of the experts.

$$
\begin{aligned}
& M_{i j}=\left(l_{i j}, m_{i j}, u_{i j}\right), \\
& l_{i j}=\min \left(B_{i j k}\right), \\
& m_{i j}=\sqrt[n]{\prod_{k=1}^{n} B_{i j k}}, \\
& u_{i j}=\max \left(B_{i j k}\right),
\end{aligned}
$$

where $B_{i j k}$ in Eqs. (11), (12), (13) and (14) represents the judgment of an expert $k$ in expressing the relative importance of the two criteria $C_{i}, C_{j}$. In the EA method, for each of the rows of the pairwise comparison matrix, the value $S_{k}$, which itself is a triangular fuzzy number, is calculated as follows in Eq. (15):

$$
S_{k}=\sum_{j=1}^{n} M_{k j} \times\left[\sum_{i=1}^{m} \sum_{j=1}^{n} M_{i j}\right]^{-1},
$$

where $k$ denotes the row numbers, and $i$ and $j$ represent the options and indices, respectively. In this method, after calculating $S_{k}$, their magnitude with respect to each other should also be calculated. In general, if $M_{1}$ and $M_{2}$ are two triangular fuzzy numbers, the magnitude $M_{1}$ is defined in Eq. (16) (Sevkli et al. 2012):

$$
\begin{cases}V\left(M_{1} \geq M_{2}\right)=1 & m_{2} \geq m_{1} \\ V\left(M_{1} \geq M_{2}\right)=0 & L_{1} \geq U_{2}\end{cases}
$$

Otherwise, $V\left(M_{1} \geq M_{2}\right)=h g t\left(M_{1} \cap M_{2}\right)$.

Moreover, Eq. (17) is given as follows:

$$
\operatorname{hgt}\left(M_{1} \cap M_{2}\right)=\frac{u_{1}-L_{2}}{\left(u_{1}-L_{2}\right)+\left(m_{2}-m_{1}\right)} .
$$

The magnitude of a triangular fuzzy number of $k$ is also obtained from the following triangular fuzzy number: 


$$
\left(M_{1} \geq M_{2}, \ldots, M_{k}\right)=V\left(M_{1} \geq M_{2}\right) \text { and } \ldots \text { and } V\left(M_{1} \geq M_{k}\right)
$$

More so, we use Eq. (19) to calculate the weight of the indices in the pairwise comparison matrix:

$$
\left(x_{i}\right)=\min \left\{V\left(S_{i} \geq S_{k}\right)\right\} k=1,2, \ldots, n, k \neq i
$$

Therefore, the weight vector of the indices is as follows:

$$
w^{\prime}=\left[W\left(C_{1}\right), W\left(C_{2}\right), \ldots, W\left(C_{n}\right)\right]^{T}
$$

which is the vector of fuzzy non-normal coefficients.

The last step is to normalize the vector $w^{\prime}$ and obtain the normalized weight vector $W$, which is obtained by Eq. (21) (Dargi et al. 2014).

$$
W_{i}=\frac{W_{i}^{\prime}}{\sum W_{i}^{\prime}}
$$

\section{Fuzzy ANP technique}

The ANP is one of the multi-criteria decision-making techniques; it is the developed form of the AHP (Lee et al. 2011). This method is used to solve problems in which criteria and alternatives are not independent. ANP is in the AHP format based on the Markov chain and has a nonlinear dynamic structure (Ouyang et al. 2013). In the ANP process, the measurement of relative-importance values, such as in the AHP method, is performed with pairwise comparisons ( Deniz 2017). The steps of the ANP approach are as follows:

\section{Step 1. Design the model (network) analysis}

The criteria that are relevant in the final decision and are identified by expert opinion are linked to each other to constitute the network structure.

\section{Step 2. Use the fuzzy AHP technique for the main criteria}

The weight of all the standard criteria, regardless of internal relations, is calculated by using the fuzzy AHP technique (Saaty and Takizawa 1986), which is presented in Section 3.3. The results of this stage are shown by vector $W$.

\section{Step 3. Calculate the interactions between the criteria}

At this stage, the interactions between the criteria are determined. Experts analyze the impacts of all criteria again through pairwise comparisons. For each criterion, the pairwise comparison matrices are formed. These matrices are necessary to determine the relative effects of dependency relationships. The normalized eigenvector for these matrices is then calculated and shown as column elements in the matrix $B$ of the dependence of the weights. In this matrix $B$, the zeros are considered as criteria for the weights of the eigenvector, which exhibits no internal correlation. 


\section{Step 4. Calculate the relative dependencies of the criteria}

The relative dependencies of the criteria are calculated by combining the results of the two previous steps. The purpose of the integration is to apply the coefficients of the interdependence matrix $(B)$ to the results of the fuzzy AHP process $(W)$.

The integration of these two is the fuzzy ANP process that is obtained by Eq. (22).

$$
\omega_{c}=B W
$$

\section{BWM}

In multi-criteria decision-making methods, several options are evaluated by using several indicators to select the best option. The BWM method is one of the new decision-making methods that was presented by Rezaei (2015) and has so far been used in some studies (van de Kaa et al. 2017). Based on the BWM method, the best and the worst indicators are determined by the decision-maker, and a pairwise comparison is conducted between each of these two (the best and the worst) indicators and other indicators. A minimum-maximum problem is then formulated and solved to determine the weights of various indices (Hafezalkotob and Hafezalkotob 2017). Moreover, a formula is used in this method to calculate the inconsistency rate and check the validity of the comparisons. Among the distinguishing features of this method, the following strengths can be mentioned, given the features of other multi-criteria decision-making methods:

- It needs fewer comparative data.

- This method leads to a more robust comparison, which means that it provides more reliable answers (Rezaei 2015).

The steps of the BWM approach are as follows (Rezaei 2015):

\section{Step 1. Determine the set of decision indicators}

The set of indicators is defined as $\left\{c_{1}, c_{2}, \ldots, c_{n}\right\}$, which is required to make a decision.

\section{Step 2. Identify the best (more important, more desirable) and the worst (the least importance and least desirability) indicators}

The decision-maker defines the best and the worst indicators in general; no comparison is made at this stage.

\section{Step 3. Determine the preference of the best index over the other indexes with numbers from 1 to 9 .}

The preference vector of the best index over the other indexes is displayed as $A_{B}=\left(a_{B 1}, a_{B 2}, \ldots, a_{B n}\right)$. In the aforementioned vector, $a_{B j}$ indicates that the best index $(B)$ is preferred to index $(j)$, and it is clear that $a_{B B}=1$. 


\section{Step 4. Determine the preference of all indices over the worst indicator with numbers from 1 to 9}

The vector of precedence of other indices relative to the worst indicator is $A_{W}=$ $\left(a_{1 W}, a_{1 W}, \ldots, a_{n W}\right)^{\mathrm{T}}$. In the above consideration, $a_{j W}$ is the index preference $(j)$ relative to the worst index $(W)$, it is evident that $a_{W W}=1$.

\section{Step 5: Find the optimal weights $\left(w_{1}^{*}, w_{2}^{*}, \ldots, w_{n}^{*}\right)$}

To determine the optimal weight of each of the indexes, the pairs $\frac{w_{B}}{w_{j}}=a_{B j}$ and $\frac{w_{j}}{w_{w}}=a_{j w}$ are formed. We must then find a solution to satisfy these conditions in all $j$ to maximize the terms $\left|\frac{w_{B}}{w_{j}}-a_{B j}\right|$ and $\left|\frac{w_{j}}{w_{w}}-a_{j w}\right|$ for all $j$ that are minimized. Regarding the non-negative weights and the total weights, the model can be formulated as follows:

$$
\begin{gathered}
\underset{\operatorname{minmax}_{j}}{ }\left\{\left|\frac{w_{B}}{w_{j}}-a_{B j}\right|,\left|\frac{w_{j}}{w_{w}}-a_{j w}\right|\right\} \\
\sum_{j} w_{j}=1 ; w_{j} \geq 0, \text { for all } j .
\end{gathered}
$$

The above model can also be converted to the following model:

$$
\begin{gathered}
\min \xi, \\
\text { s.t. } \\
\left|\frac{w_{B}}{w_{j}}-a_{B j}\right| \leq \xi, \text { for all } j, \\
\left|\frac{w_{j}}{w_{w}}-a_{j w}\right| \leq \xi, \text { for all } j, \\
\sum_{j} w_{j}=1 ; w_{j} \geq 0, \text { for all } j .
\end{gathered}
$$

Hence, the linear model of the above function is presented as follows (Rezaei 2016; Salimi 2017). In this study, weights of indexes are obtained by using a linear model.

$$
\begin{gathered}
\min \xi \\
\text { s.t. } \\
\left|w_{B}-a_{B j} w_{j}\right| \leq \xi, \text { for all } j \\
\left|w_{j}-a_{j w} w_{w}\right| \leq \xi, \text { for all } j \\
\sum_{j} w_{j}=1 ; w_{j} \geq 0, \text { for all } j .
\end{gathered}
$$

By solving the above model, the optimal values of $\left(w_{1}^{*}, w_{2}^{*}, \ldots, w_{n}^{*}\right)$ and $\xi^{*}$ are obtained.

\section{Calculating the compatibility rate in the BWM method}

Using the obtained $\xi^{*}$, the compatibility rate is calculated. The larger $\xi^{*}$ evidently represents the higher compatibility rate. Since $a_{B j} \times a_{j w}=a_{B W}$ and $a_{B W} \in\{1,2, \ldots, 9\}$, the maximum value of $\xi$ can be obtained. Thus, using the compatibility indexes in Table 3 and Eq. (24), the compatibility rate can be calculated. 
Table 3 Compatibility indices using the BWM method

\begin{tabular}{llllllllll}
\hline $\mathrm{a}_{B W}$ & 1 & 2 & 3 & 4 & 5 & 6 & 7 & 8 & 9 \\
\hline Compatibility index & 0.00 & 0.44 & 1.00 & 1.63 & 2.30 & 3.00 & 3.73 & 4.47 & 5.23 \\
\hline
\end{tabular}

Compatibility rate $=\frac{\xi^{*}}{\text { Compatibility index }}$.

The closer the compatibility rates are to zero, the more consistent the results. It should be noted that in the linear model, compatibility rates are not required. Moreover, the less the $\xi^{*}$, the more consistent the results (Rezaei 2016).

\section{Case study}

The results of the Delphi technique

The target population of this research consists of 30 managers, senior managers, and experts who are active at central offices (Tehran) of the first-rate companies of Iran's PSP industry and have more than 10 years of experience in the field. Based on the Delphi method, risks are identified and categorized by conducting a series of interviews with all the experts. It should be noted that due to the nature of the DEMATEL and ANP techniques, the risks are reduced as much as possible. Thus, certain criteria have been combined based on their content compatibility with the titles that include the desired criteria, which are used in the subsequent stages. Finally, 11 major risks and 46 sub-risks are selected as important risks for the final solution of the model. The risks are presented in Table 4.

The results of the fuzzy DEMATEL technique

The result of the implementation of the fuzzy DEMATEL technique is shown in Fig. 3.

Implementation of the fuzzy ANP and the fuzzy AHP techniques

Structuring the analysis model (network)

At this stage, the risks involved in the final decision are linked to each other by a panel of experts, thus creating a network structure in the previous step (FDEMATEL technique).

Thus, to illustrate the relationships between the criteria and maintain the complexity of the system with a manageable level simultaneously, it is necessary to adjust a threshold value to filter out the negligible effects. Hence, only some criteria whose impacts are greater than the threshold value should be selected and displayed on the network relationship map. It is sufficient to calculate the average of the total defuzzified relationship matrix values. Moreover, all values smaller than the threshold value (considered as 0.222 in this study) are assumed to be zero, and their causal relationships are not considered (Chiu et al. 2013). Therefore, Fig. 3 illustrates the relationship network.

\section{Calculating the interactions between criteria}

The next step is measuring and collecting data, which involves collecting expert information for judgment on pairwise comparisons. Due to the fuzzy nature of the method, scales in Table 5 are used to measure pairwise comparisons. Since the pairwise matrix represents the expert opinions, fuzzy numbers adequately integrate the scattered judgments of the experts. Regardless of the relationship between criteria, experts were asked 
Table 4 The risks of losing banking projects in PSP companies

Main risks

Recipient production process $(\mathrm{A})$

Terminal establishment process (B)

Supporting process (C)

Recipient retention and satisfaction process (D)

Executive interaction with bank (E)

The terms of contract and commitment (F)

Company credibility and power $(\mathrm{G})$

Efficiency of agencies $(\mathrm{H})$

\section{Sub-risks}

A1: Inappropriate marketing of the executive staff

A2: Inappropriate marketing of the bank

A3: Inappropriate marketing of the agencies

A4: Absence of a suitable program for identifying and attracting specific recipients(VIPs)

B1: No timely allocation of the devices

B2: No timely installation of the devices

B3: Lack of adequate training of staff on how to work with the devices

C1: No timely repairing of faulty terminals

C2: Undesirable rolled up to the recipients

C3: Inappropriate call center response to financial problems

D1: Failure to provide the devices with desirable quality and hardware specifications

D2: Inappropriate quality of device software

D3: Frequent technical problems

D4: Failure to meet customer needs

D5: Not paying attention to specific recipients (VIPS)

D6: No paying attention to complaints

D7: Lack of suitable program for keeping specific recipients (VIPS)

E1: Successive changes of the project managers and experts

E2: Changes of bank managers and their approaches to the PSP company

E3: Inappropriate strategy of central office personnel

E4: Failure to comply with work ethics

E5: No timely response to bank requests

E6: Timely request for status

E7: Inappropriate behavior of personnel of agencies with the bank branches

E8: Bank's dissatisfaction with the company

E9: No timely delivery of the devices

E10: Repeating infringements

E11: Failure to provide reports and clarifications for highlighting company achievements

F1: Inappropriate contract with unreasonable terms

F2: Failure to adhere to the terms of the contract and mutual obligations

F3: Lack of proper planning for achieving the goals of the project F4: Disclosure of confidential information and documents of bank's customers

G1: Background of failure in other banking projects

G2: Increasing dissatisfied recipients

G3: Absorbing undesirable recipients

G4: Decreasing special recipients (VIPS) and attracting them by competitors

G5: Lack of covering the operating costs with incoming payments

$\mathrm{H1}$ : The inability and inappropriate financial situations of the provincial agencies 
Table 4 The risks of losing banking projects in PSP companies (Continued)

\begin{tabular}{ll}
\hline Main risks & Sub-risks \\
\hline & H2: No financial support of agencies from the central office \\
T3: Lacking sufficient standards and capabilities \\
I1: Failure to establish a secure, stable and high-speed network \\
I2: Failure to quickly implement market needs \\
J1: Lack of innovation and initiative in accordance with customer needs \\
J2: Lack of study and identification of market needs \\
J3: Being behind of competitive market \\
K1: Being unknown in the market \\
K2: Lack of a quick notification of the company's latest achievements for \\
market penetration
\end{tabular}

to evaluate the criteria based on pairwise comparisons. They answered the following question: Which risk has more impacts than the others, and to what extent?

In addition to forming a matrix of total risk pairwise comparisons, the matrices of the pairwise comparisons are to be compared with the internal factors. Therefore, according to Table 4, the risks associated with each other are first identified. The matrices of pairwise comparisons are then formed. Dimensions of the matrices of pairwise comparisons required for each of the internal risks are presented in Table 6.

The geometric mean of expert opinions is then calculated for each risk. Table 7 shows the result of the average expert opinions regarding the main risks of this research.

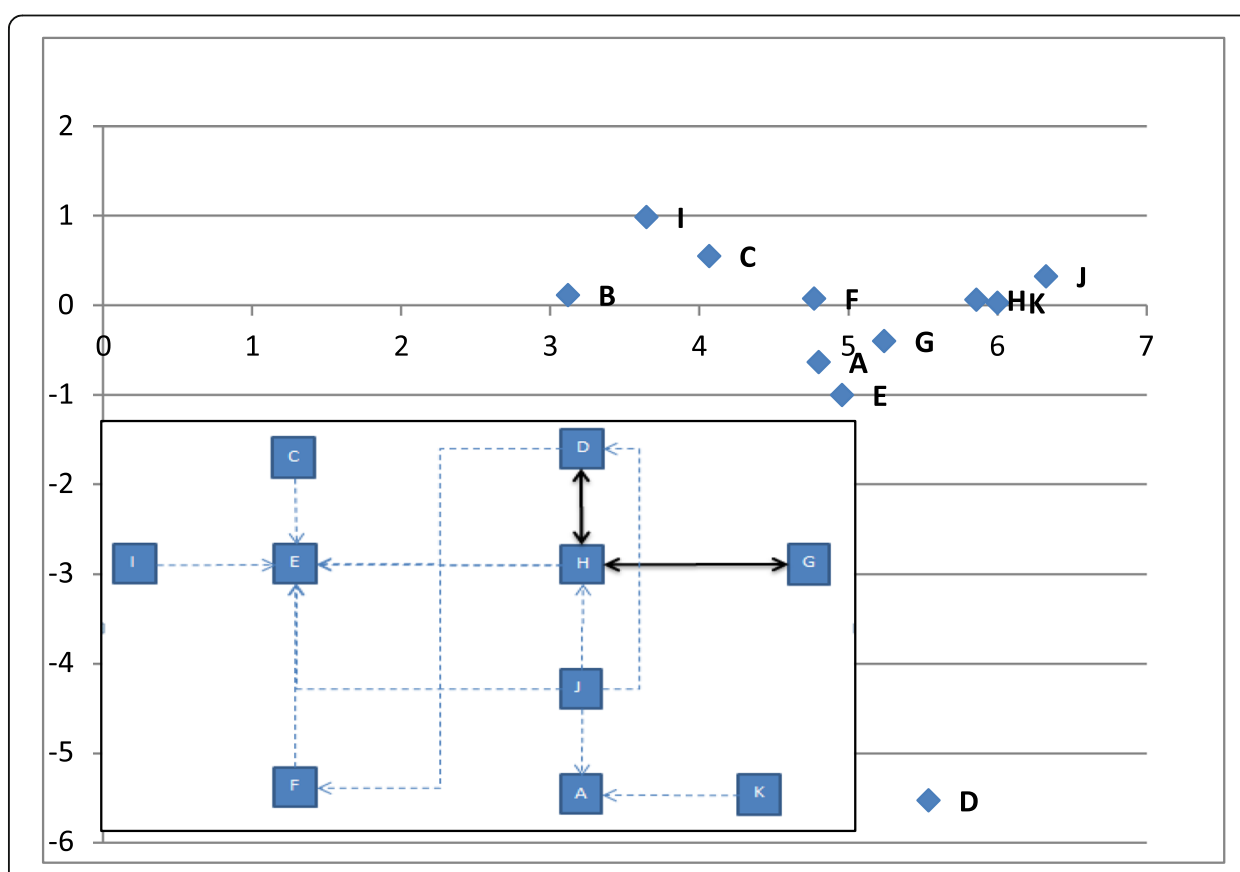

Fig. 3 Cause and effect diagram of the main risks 
Table $\mathbf{5}$ Linguistic phrases and fuzzy numbers for comparing the preferences of the criteria

\begin{tabular}{lll}
\hline Linguistic scale relative priority & Triangular fuzzy scale & Triangular fuzzy scale of the opposite side \\
\hline Equally important & $(1,1,1)$ & $(1,1,1)$ \\
Almost equally important & $(1 / 2,1,3 / 2)$ & $(2 / 3,1,2)$ \\
Relatively important & $(1,3 / 2,2)$ & $(1 / 2,2 / 3,1)$ \\
Important & $(3 / 2,2,5 / 2)$ & $(2 / 5,1 / 2,2 / 3)$ \\
Great importance & $(2,5 / 2,3)$ & $(1 / 3,2 / 5,1 / 2)$ \\
Absolutely important & $(5 / 2,3,7 / 2)$ & $(2 / 7,1 / 3,2 / 5)$ \\
\hline
\end{tabular}

Source: Sinrat and Atthirawon 2015

The final weights of risks based on the fuzzy DEMATEL-ANP technique

The final weights obtained from the implementation of the fuzzy DEMATEL and fuzzy ANP techniques are displayed in Table 8, and the risk rankings are shown in Fig. 4. Since the identified sub-risks did not affect each other, a fuzzy AHP method was used to identify their weights.

\section{The sensitivity analysis of the fuzzy DEMATEL-ANP model}

Sensitivity analysis makes it possible to consider the different values of decision-making variables. There may be cases where, despite variable changes, the final output will not considerably change. In this case, the final decision is not sensitive to that variable. In some cases, however, small changes in some variables completely change the outcome of a decision. In this research, a sensitivity analysis is conducted by changing the values of the main factors according to the weights ( $w$ from Eq. [21]), which is the input of the ANP technique.

Case 0 shows the main weights obtained from $w$, while Cases 1, 2, and 3 are the probable values of $w$ for $\mathrm{E}, \mathrm{B}$, and $\mathrm{D}$ risks, which are respectively the most significant risk, the least important risk, and the intermediate risk. The final rankings of risks based on the probable cases are shown in Table 9, which depicts the rankings based on the changes. The results indicate that, in the real world, the actual situation and expert judgment should be considered for determining the appropriate weights of factors to

Table 6 Dimensions of the matrices of pairwise comparisons based on the internal relationships between the main risks

\begin{tabular}{lll}
\hline Risks & Related risks & Dimension of pairwise comparison matrices \\
\hline A & - & - \\
B & - & - \\
C & E & - \\
D & F, H & $2 \times 2$ \\
E & - & - \\
F & E & - \\
G & H & - \\
H & D, E & $2 \times 2$ \\
I & G & - \\
J & A, D, E, H & $4 \times 4$ \\
K & A & - \\
\hline
\end{tabular}




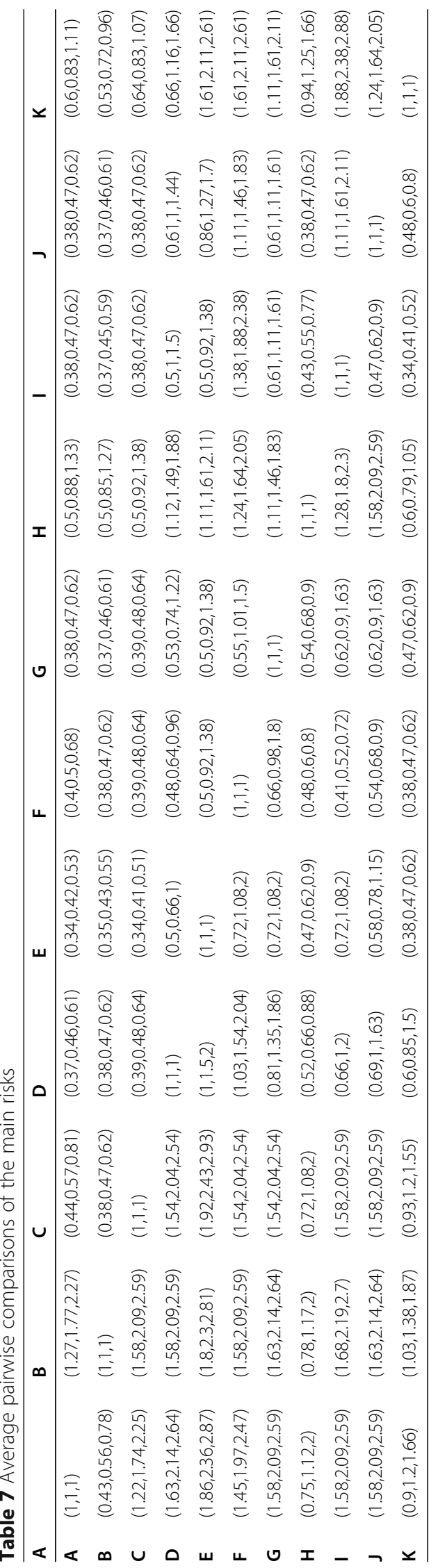


Table 8 The final weights of the fuzzy DEMATEL-ANP decision-making technique

Mecipient production process (A)

Terminal establishment process (B)

Supporting process $(C)$

Recipient retention and satisfaction process (D)

Executive interaction with bank (E)

The terms of contract and commitment ( $F$

\section{Sub-risks}

Weights

0.074

A1: Inappropriate marketing of the executive staff

0.2711

A2: Inappropriate marketing of the bank

0.2211

A3: Inappropriate marketing of the agencies

0.097

A4: Absence of a suitable program for identifying and attracting specific recipients (VIPS)

0.4108

\subsection{6}

B1: No timely allocation of the devices

0.3723

B2: No timely installation of the devices

B3: Lack of adequate training of staff on how to work with the devices

\subsection{1}

C1: No timely repairing of faulty terminals

C2: Undesirable rolled up to the recipients

0.2693

C3: Inappropriate call center response to financial problems

0.094

D1: Failure to provide the devices with desirable quality and hardware specifications

D2: Inappropriate quality of device software

0.1069

D3: Frequent technical problems

0.1711

D4: Failure to meet customer needs

0.1854

0.0989

D5: Not paying attention to specific recipients (VIPS)

0.1522

D6: No paying attention to complaints

0.2124

D7: Lack of suitable program for keeping specific recipients (VIPS)

0.073

0.218

E1: Successive changes of the project managers and

0.0043 experts

0.0875

the PSP company

E3: Inappropriate strategy of central office personnel

0.1141

E4: Failure to comply with work ethics

0.1192

E5: No timely response to bank requests

0.1006

E6: Timely request for status

0.1054

E7: Inappropriate behavior of personnel of agencies with the bank branches

E8: Bank's dissatisfaction with the company

0.109

E9: No timely delivery of the devices

0.1589

E10: Repeating infringements

0.0557

0.1092

E11: Failure to provide reports and clarifications for highlighting company achievements

0.0361

0.099

F1: Inappropriate contract with unreasonable terms

0.2676

F2: Failure to adhere to the terms of the contract and mutual obligations

F3: Lack of proper planning for achieving the goals of the project 
Table 8 The final weights of the fuzzy DEMATEL-ANP decision-making technique (Continued)

Main risks

Efficiency of agencies $(\mathrm{H})$

Technical and operational (I)

Research and development (J)

Advertising $(K)$

\section{Sub-risks}

Weights

F4: Disclosure of confidential information and documents 0.3341 of bank's customers

Company credibility and power (G)

G1: Background of failure in other banking projects

0.16

G2: Increasing dissatisfied recipients

0.2393

G3: Absorbing undesirable recipients

0.1613

G4: Decreasing special recipients (VIPS) and attracting them by competitors

G5: Lack of covering the operating costs with incoming payments

0.2299

0.2585

0.125

$\mathrm{H} 1$ : The inability and inappropriate financial situations of the provincial agencies

$\mathrm{H}$ 2: No financial support of agencies from the central office

H3:Lacking sufficient standards and capabilities

0.2064

0.5475

0.071

11: Failure to establish a secure, stable and high-speed network

12: Failure to quickly implement market needs

0.5113

0.4887

0.068

J1: Lack of innovation and initiative in accordance with customer needs

J2: Lack of study and identification of market needs

0.2405

J3: Being behind of competitive market

0.378

0.3815

0.031

K1: Being unknown in the market

0.5246

K2: Lack of a quick notification of the company's latest achievements for market penetration

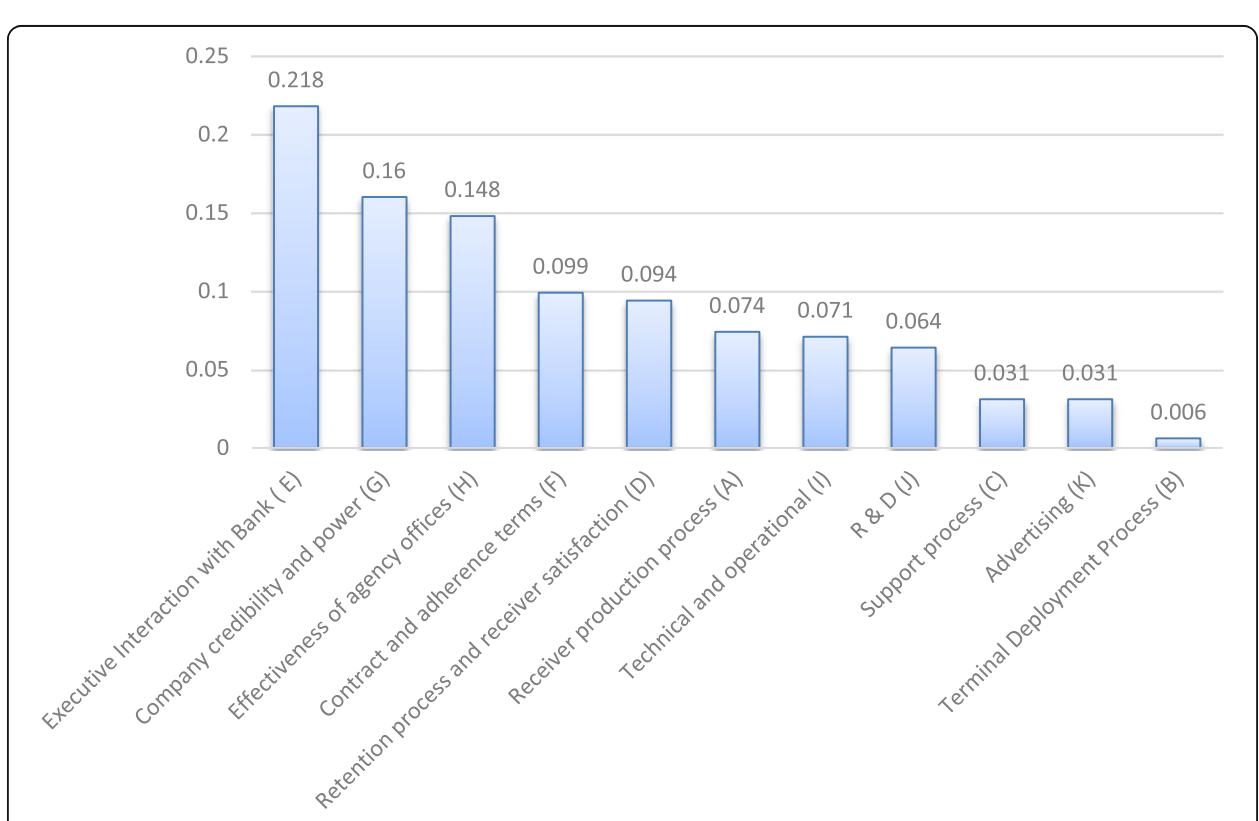

Fig. 4 Prioritization of the major risks of PSP companies based on the fuzzy DEMATEL-ANP approach 
Table 9 The final rankings of risks

\begin{tabular}{lllll}
\hline & Case 0 & Case 1 & Case 2 & Case 3 \\
\hline & $A H P_{E}=0.1369$ & $A H P_{E}=0.1069$ & $A H P_{E}=0.0769$ & $A H P_{E}=0.0069$ \\
& $A H P_{B}=0.0114$ & $A H P_{B}=0.1114$ & $A H P_{B}=0.0104$ & $A H P_{B}=0.0314$ \\
& $A H P_{D}=0.1109$ & $A H P_{D}=0.0409$ & $A H P_{D}=0.1719$ & $A H P_{D}=0.2209$ \\
A & 6 & 5 & 6 & 6 \\
B & 11 & 8 & 11 & 11 \\
C & 9 & 10 & 9 & 9 \\
$\mathbf{D}$ & 5 & 9 & 4 & 3 \\
$\mathbf{E}$ & 1 & 1 & 1 & 4 \\
$\mathbf{F}$ & 4 & 4 & 5 & 5 \\
$\mathbf{G}$ & 2 & 2 & 3 & 2 \\
$\mathbf{H}$ & 3 & 3 & 2 & 7 \\
$\mathbf{I}$ & 7 & 6 & 7 & 8 \\
$\mathbf{J}$ & 8 & 7 & 8 & 10 \\
$\mathbf{K}$ & 10 & 11 & 10 & \\
\hline
\end{tabular}

prioritize the project's failure risks and corrective actions (Liu et al. 2014). The results of sensitivity analysis are presented in Fig. 5.

\section{Implementing the BWM technique on main risks}

At this stage, we obtain weights for each of the identified major risks with the BWM method. Thus, the BWM specific questionnaire was first distributed among the 10 more experienced experts in this field who participated in previous research techniques; each of them was asked to identify the most important and the least significant risks. In the next step, the priority vector of the most important factor was determined by comparison with other factors. Thus, to determine this vector, the experts were asked to indicate the priority of the most important factor from the other factors on a scale of 1 to 9 . The preference vector of the other factors is then assigned to the least important factor. This vector was determined by the same method as the previous step. The optimal weights can then be obtained via the described relationship. Finally, by solving the above models with the LINGO11 software, the optimal values of $\left(w_{1}^{*}, w_{2}^{*}, \ldots, w_{n}^{*}\right)$ and $\xi^{*}$ for each of the research factors, as well as the 10 researchers, were achieved. Hence, to

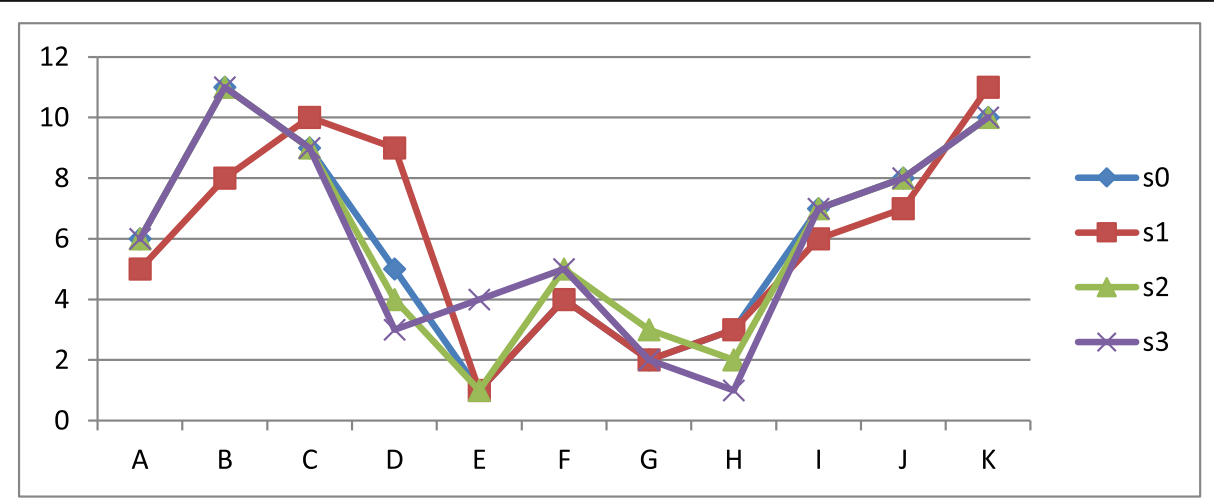

Fig. 5 The results of the sensitivity analysis of the fuzzy DEMATEL-ANP approach 
Table 10 The final weights of the risks obtained by BWM

\begin{tabular}{ll}
\hline Risk & Risk weight \\
\hline Recipient production process (A) & 0.062355 \\
Terminal establishment process (B) & 0.024552 \\
Supporting process (C) & 0.047682 \\
Recipient retention and satisfaction process (D) & 0.071893 \\
Executive interaction with bank (E) & 0.248863 \\
The terms of contract and commitment (F) & 0.093935 \\
Company credibility and power (G) & 0.187903 \\
Efficiency of agencies (H) & 0.121075 \\
Technical and operational (I) & 0.054921 \\
Research and development (J) & 0.047081 \\
Advertising (K) & 0.039740 \\
\hline
\end{tabular}

calculate the final combined weights of each research factor and 10 experts involved in the research, the arithmetic mean should be taken. The results of the final weights of these factors are presented in Table 10. Based on the obtained weights by the BWM method, Fig. 6 shows the rankings of the main risks.

Therefore, by solving the linear programming model of the BWM for each expert and calculating the aggregate weights, the factors of the executive interaction with the bank, the credibility and power of the company, and the efficiency of the agencies are introduced, respectively, as the most important factors. Since the value $\xi^{*}$ of each expert should be considered in the linear model to determine the inconsistency of expert judgments, and every $10 \xi^{*}$ were

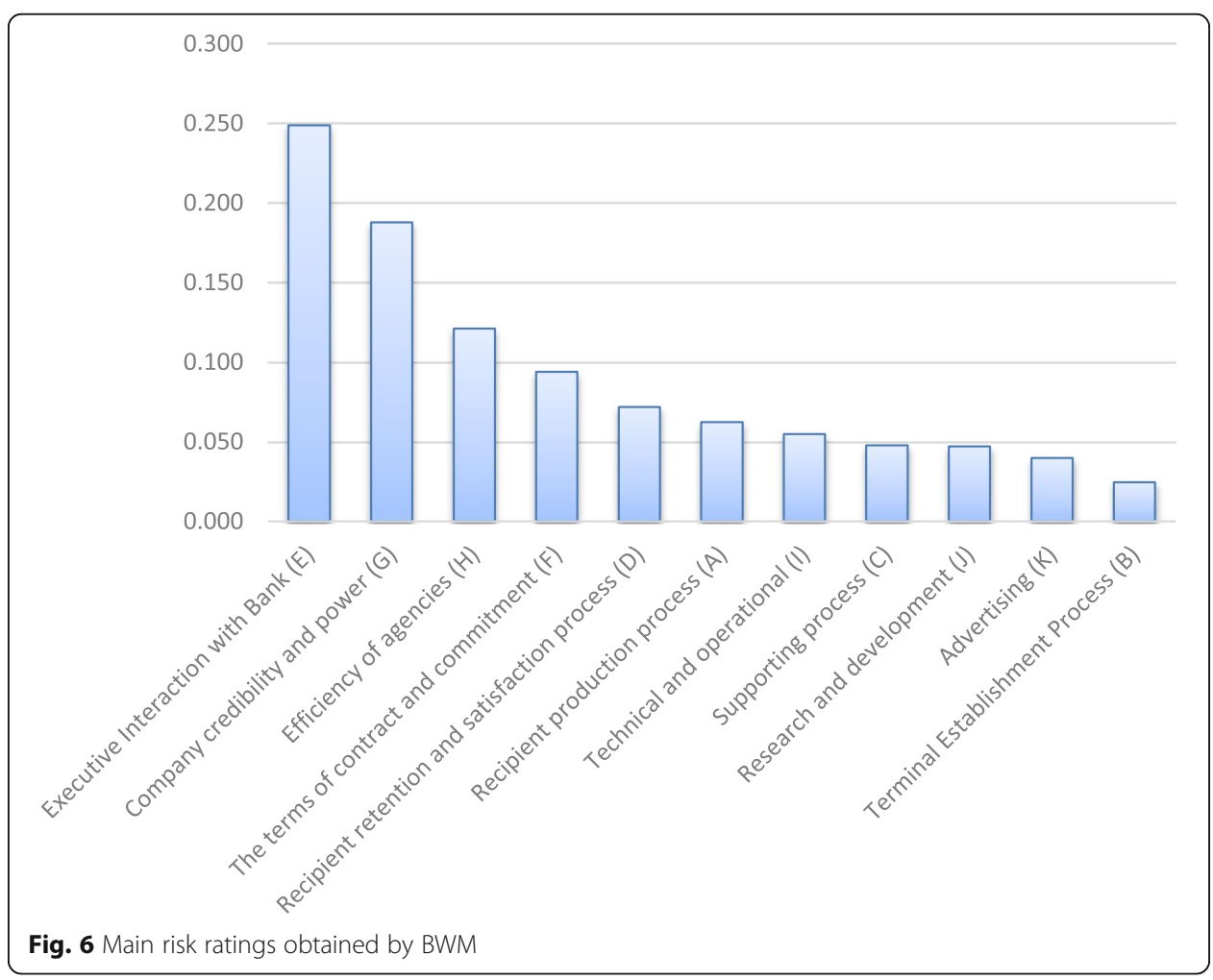


at the acceptable level, the compatibility level of the linear model of each expert is also acceptable.

The comparison between the results of rankings based on the fuzzy DEMATEL-ANP and BWM techniques

The comparison between the ranking differences based on the decision-making methods used in this study is depicted in Fig. 7.

\section{Conclusions}

Expanding the activity of non-bank PSPs and applying new payment technologies, as well as increasing the use of new and effective payment methods, are key goals in the future development of cashless settlements. The modern economy needs a vast network of PSPs to make electronic payment services available to everyone. This broad network of PSPs must assess all their plans and identify all risks and evaluate them carefully to uphold the mutual trust between both banks and financial institutions, and service customers.

Furthermore, the identification of the risks and their causal relationships regarding the Iranian PSP industry (which is unique because of its own specifications and characteristics) has not yet been studied. Moreover, the BWM method has not been used for risk prioritization. Identifying critical risks and prioritizing them plays an important role in the success of the banking projects of the companies and provides the basis for contracting with the other banks. If PSPs can build a reputation for themselves by implementing risk management, they can gain the trust of banks, which can increase the number of customers and contracts with banks (Jiang et al. 2009). The outcomes of

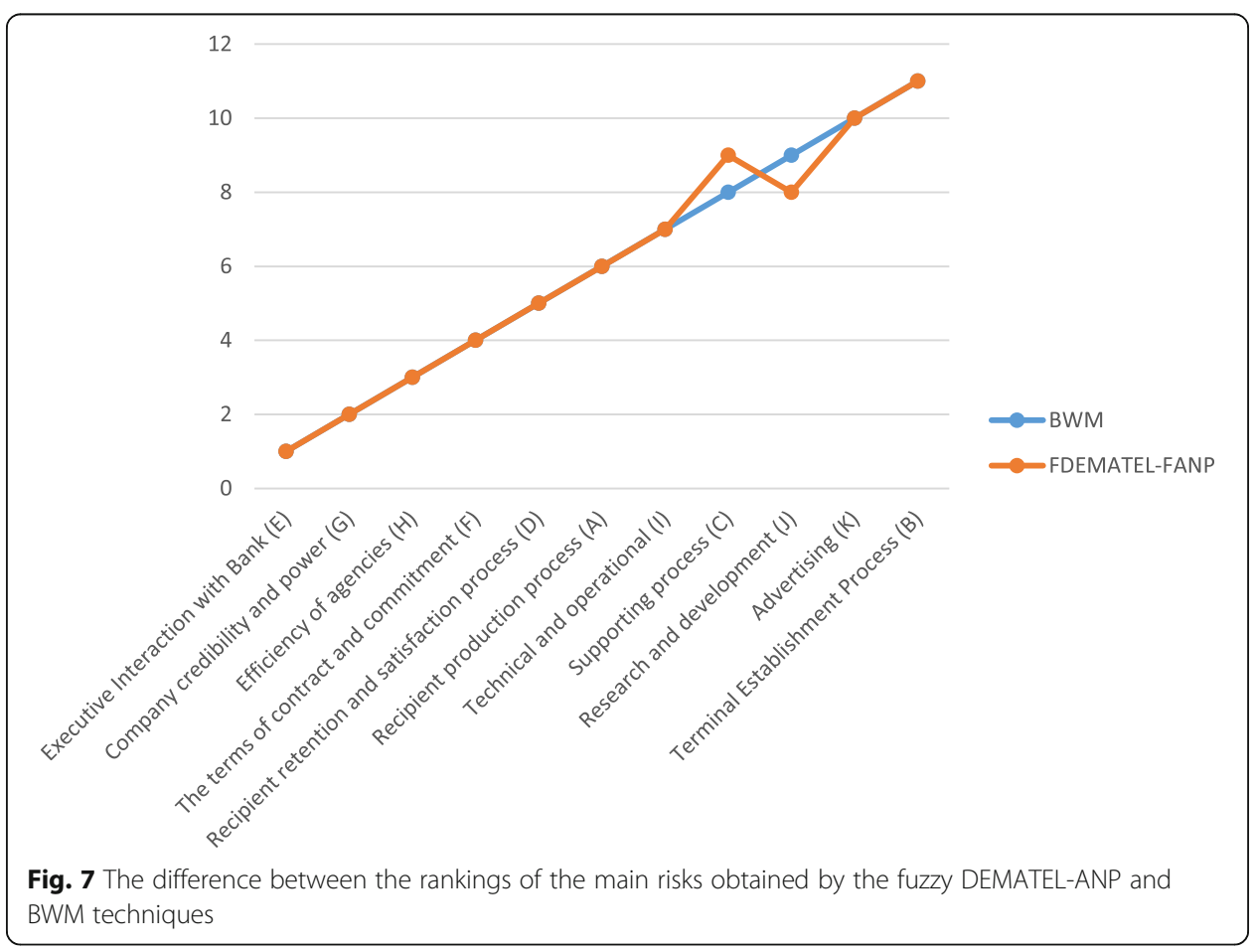


this research are based on the prioritization and importance of the known risks in this industry. Since the PSP industry is rapidly changing, the risks varies; therefore, the ranks are not static. The results of this study help managers identify effective risks and provide scope for future research. Due to the lack of a comprehensive database, the data are gathered through expert judgement. The scope of this research is limited to Iranian PSP companies, and this study can be expanded to other countries. Regarding future studies, the identified risks should be updated based on varying market conditions. More so, other multi-criteria decision-making methods may be used, and the results must be compared. The uncertainty and ambiguity of the subjective opinions of experts should be considered by using other theories such as the gray theory and the theory of intuitive sets. Finally, the risk responses and appropriate solutions should be evaluated, and the best ones should be selected via the process of risk management.

Acknowledgements

There is no need for acknowledgement.

\section{Authors' contributions}

Dr. Mohammad Khalilzadeh is the corresponding author and the main researcher of the study, in which $50 \%$ of the whole job have been written and calculated by him with collaboration and assistance of Ms. Laleh Katouizadeh who assisted with writing the manuscript, gathering and analyzing the data gathering. Professor Edmundas Kazimieras Zavadskas supervised this research.

All authors read and approved the manuscript.

Funding

Funding information is not available and not applicable.

Availability of data and materials

Available upon request.

Competing interests

The author declares that there are no conflicts of interests in this paper.

\section{Author details}

${ }^{1}$ CENTRUM Católica Graduate Business School, Lima, Peru. ²Pontificia Universidad Católica del Perú, Lima, Peru. ${ }^{3}$ Department of Industrial Engineering, Science and Research Branch, Islamic Azad University, Tehran, Iran. ${ }^{4}$ Vilnius Gediminas Technical University, Institute of Sustainable Construction, Vilnius, Lithuania.

Received: 2 December 2019 Accepted: 2 June 2020

Published online: 06 July 2020

\section{References}

Antcliff, D., Keeley, P., Campbell, M., Oldham, J., \& Woby, S. (2013). The development of an activity pacing questionnaire for chronic pain and/or fatigue: A Delphi technique. Physiotherapy, 99(3), 241-246.

Bauer, H., Barnes, S., Reichardt, T., \& Neumann, M. (2005). Driving consumer acceptance of mobile marketing: Atheoretical framework and empirical study. Journal of Electronic Commerce and Research, 6(3), 181-191.

Chang, D. Y. (1996). Applications of the extent analysis method on fuzzy AHP. European Journal of Operational Research, 25(3), 649-655.

Chauhan, A., Singh, A., \& Jharkharia, S. (2016). An interpretive structural modeling (ISM) and decision-making trail and evaluation laboratory (DEMATEL) method approach for the analysis of barriers of waste recycling in India. Journal of the Air \& Waste Management Association, 68(2), 100-110.

Chen, Y. S., Lin, C. K., \& Chuang, H. M. (2016). Improving project risk management of cloud CRM using DANP approach. In J. Hung, N. Yen, \& K. C. Li (Eds.), Frontier Computing. Lecture notes in electrical engineering (Vol. 375). Singapore: Springer.

Chiu, W.-Y., Tzeng, G.-H., \& Li, H.-L. (2013). A new hybrid MCDM model combining DANP with VIKOR to improve e-store business. Knowledge-Based Systems, 37, 48-61.

Cooper, D., Grey, S., Raymound, G., \& Walker, P. (2005). Project risk management guidelines: Managing risk in large projects and complex procurements. England: Wiley.

Cowan, D., Brunero, S., Lamont, S., \& Joyce, M. (2015). Direct care activities for assistants in nursing in inpatient mental health settings in Australia : A modified Delphi study. Collegian, 22(1), 53-60.

Dargi, A., Anjomshoae, A., Galankashi, M. R., Memari, A., \& Tap, M. B. M. (2014). Supplier selection: A fuzzy-ANP approach. Procedia Computer Science, 31, 691-700.

Dehdasht, G., Mohamad Zin, R., Ferwati, M., Mohammed Abdullahi, M., Keyvanfar, A., \& McCaffer, R. (2017). DEMATEL-ANP risk assessment in oil and gas construction projects. Sustainability, 9(8), 1420.

Deniz, G. O. (2017). An analytic network process (ANP) model to examine LEED-certified buildings' operational performance. Built Environment Project and Asset Management, 7(4), 366-376.

Diao, H., \& Ghorbani, M. (2018). Production risk caused by human factors: A multiple case study of thermal power plants. Frontiers of Business Research in China, 12(3), 296-322. 
Fazli, S., Kiani Mavi, R., \& Vosooghidizaji, M. (2015). Crude oil supply chain risk management with DEMATEL-ANP. Operational Research, 15(3), 453-480.

Ghandehary, M., Harati, H., \& Khazaei Pool, J. (2014). Identifying and ranking the effective factors on customer values. Education, Business and Society: Contemporary Middle Eastern Issues, 7(1), 57-74.

Ghassemi, A., \& Darvishpour, A. (2018). A novel approach for risk evaluation and risk response planning in a geothermal drilling project using DEMATEL and fuzzy ANP. Decision Science Letters, 7, 225-242.

Habibi, A., Sarafrazi, A., \& Izadyar, S. (2014). Delphi technique theoretical framework in qualitative. International Journal of Engineering Science, 3(4), 8-13.

Hafezalkotob, A., \& Hafezalkotob, A. (2017). A novel approach for combination of individual and group decisions based on fuzzy best-worst method. Applied Soft Computing, 59, 316-325.

Heitz-Spahn, S. (2013). Cross-channel free-riding consumer behavior in a multichannel environment: An investigation of shopping motives, sociodemographics and product categories. Journal of Retailing and Consumer Services, 20(6), 570-578.

Xu, H., Wan, Y., \& Pei, D. (2008). A study on risk perception and risk identification in the internationalization process of Chinese hi-tech enterprises - A case study of Huawei technologies. Frontiers of Business Research in China, 2(3), 458-481.

Jiang, Q., Huang, X., \& Chen, Z. (2009). Antecedents and consequences of consumers' trust in electronic intermediaries: An empirical study of hotel booking websites. Frontiers of Business Research in China, 3(4), 647-666.

Kasap, D., \& Kaymak, M. (2007). Risk identification step of the project risk management. In Portland international conference on management of engineering and technology (pp. 2116-2120).

Kim, D. J., Ferrin, D. L., \& Rao, H. R. (2008). A trust-based consumer decision-making model in electronic commerce: The role of trust, perceived risk, and their antecedents. Decision Support Systems, 44(2), 544-564.

Kovacs, L., \& David, S. (2016). Fraud risk in electronic payment transactions. Journal of Money Laundering Control, 19(2), 148-157.

Lee, W.-S., Huang, A. Y., Chang, Y.-Y., \& Cheng, C.-M. (2011). Analysis of decision making factors for equity investment by DEMATEL and analytic network process. Expert Systems with Applications, 38(7), 8375-8383.

Liu, H.-C., Fan, X.-J., Li, P., \& Chen, Y.-Z. (2014). Evaluating the risk of failure modes with extended MULTIMOORA method under fuzzy environment. Engineering Applications of Artificial Intelligence, 34, 168-177.

Marchewka, J. (2009). Information technology project management. In Managing Project Risk (pp. 173-194). New York: Wiley.

Mohaghar, A., Sahebi, I. G., \& Arab, A. (2017). Appraisal of humanitarian supply chain risks using best-worst method. International Journal of Industrial and Manufacturing Engineering, 11, 349-354.

Mojtahedi, S. M. H., Mousavi, S. M., \& Makui, A. (2010). Project risk identification and assessment simultaneously using multiattribute group decision making technique. Safety Science, 48(4), 499-507.

Nambiar, S., \& Lu, C.-T. (2005). M-payment solutions and M-commerce fraud management. In Advances in security and payment methods for Mobile commerce (pp. 192-213). Hershey: Idea Group Publishing.

Nazeri, A., \& Naderikia, R. (2017). A new fuzzy approach to identify the critical risk factors in maintenance management. The International Journal of Advanced Manufacturing Technology, 92(9-12), 3749-3783.

Ou Yang, Y.-P., Shieh, H.-M., \& Tzeng, G.-H. (2013). A VIKOR technique based on DEMATEL and ANP for information security risk control assessment. Information Sciences, 232(20), 482-500.

Özdemir, A., \& Tüysüz, F. (2017). An integrated fuzzy DEMATEL and fuzzy ANP based balanced scorecard approach: Application in Turkish higher education institutions. Journal of Multiple-Valued Logic and Soft Computing, 28(2-3), 251-287.

Park, J., Amendah, E., Lee, Y., \& Hyun, H. (2019). M-payment service: Interplay of perceived risk, benefit, and trust in service adoption. Human Factors and Ergonomics in Manufacturing \& Service Industries, 29(1), 31-43.

Patil, S. K., \& Kant, R. (2014). Predicting the success of knowledge management adoption in supply chain using fuzzy DEMATEL and FMCDM approach. International Journal of Business Performance and Supply Chain Modelling, 6(1), 75-93.

Potdar, P. K., Routroy, S., \& Behera, A. (2017). Analyzing the agile manufacturing barriers using fuzzy DEMATEL. Benchmarking: An International Journal, 24(7), 1912-1936.

Reyes, F., Cerpa, N., Candia-Véjar, A., \& Bardeen, M. (2011). The optimization of success probability for software projects using genetic algorithms. Journal of Systems and Software, 84(5), 775-785.

Rezaei, J. (2015). Best-worst multi-criteria decision-making method. Omega, 53, 49-57.

Rezaei, J. (2016). Best-worst multi-criteria decision-making method: Some properties and a linear model. Omega, 64, 126-130.

Rose, K. H. (2013). A guide to the project management body of knowledge (PMBOK ${ }^{\ominus}$ guide) -fifth edition. Project Management Journal, 44(3). https://doi.org/10.1002/pmj.21345.

Saaty, T. L., \& Takizawa, M. (1986). Dependence and independence: From linear hierarchies to nonlinear networks. European Journal of Operational Research, 26(2), 229-237.

Saaty, T. L., \& Vargas, L. G. (2006). The analytic network process. In Decision Making with the Analytic Network Process. New York: Springer.

Salimi, N. (2017). Quality assessment of scientific outputs using the BWM. Scientometrics, 112(1), 195-213.

Sevkli, M., Oztekin, A., Uysal, O., Torlak, G., Turkyilmaz, A., \& Delen, D. (2012). Development of a fuzzy ANP based SWOT analysis for the airline industry in Turkey. Expert Systems with Applications, 39(1), 14-24.

Shieh, J.-.., Wu, H.-H., \& Huang, K.-K. (2010). A DEMATEL method in identifying key success factors of hospital service quality. Knowledge-Based Systems, 23(3), 277-282.

Sinrat, S., \& Atthirawon, W. (2015). Integrated factor analysis and fuzzy analytic network process (FANP) model for supplier selection based on supply chain risk factors. Research Journal of Business Management, 9(1), 106-123.

Slade, E. L, Dwivedi, Y. K, Piercy, N. C., \& Williams, M. D. (2015). Modeling consumers' adoption intentions of remote mobile payments in the United Kingdom: Extending UTAUT with innovativeness, risk, and trust. Psychology and Marketing, 32(8), 860-873.

Soofifard, R., Ebrahimi, M., \& Bafruei, M. K. (2017). Risk assessment of construction projects by using combined model of analytical network process and DEMATEL method. International Journal of Services and Operations Management, 28(1), 1-25.

Torabi, S. A., Giahi, R., \& Sahebjamnia, N. (2016). An enhanced risk assessment framework for business continuity management systems. Safety Science, 89, 201-218.

Tsai, W.-H., Chou, Y.-W., Lee, K.C., Lin, W.-R., \& Hwang, E. T. Y. (2013). Combining decision making trial and evaluation laboratory with analytic network process to perform an investigation of information technology auditing and risk control in an enterprise resource planning environment. Systems Research and Behavioral Science, 30(2), 176-193. 
Uygun, Ö., Canvar Kahveci, T., Taşkın, H., \& Piriştine, B. (2015). Readiness assessment model for institutionalization of SMEs using fuzzy hybrid MCDM techniques. Computers \& Industrial Engineering, 88, 217-228.

Van de Kaa, G., Kamp, L., \& Rezaei, J. (2017). Selection of biomass thermochemical conversion technology in the Netherlands: A best worst method approach. Journal of Cleaner Production, 166, 32-39.

Von der Gracht, H. A. (2012). Consensus measurement in Delphi studies. Technological Forecasting and Social Change, 79(8), 1525-1536.

Vujanović, D., Momčilović, V., Bojović, N., \& Papić, V. (2012). Evaluation of vehicle fleet maintenance management indicators by application of DEMATEL and ANP. Expert Systems with Applications, 39(12), 10552-10563.

Wachinger, G., Renn, O., Begg, C., \& Kuhlicke, C. (2013). The risk perception paradox-implications for governance and communication of natural hazards. Risk Analysis, 33(6), 1049-1065.

Wang, L., Cao, Q., \& Zhou, L. (2018). Research on the influencing factors in coal mine production safety based on the combination of DEMATEL and ISM. Safety Science, 103, 51-61.

Xu, Y., Hu, S., \& Fan, X. (2011). Entry mode choice of Chinese enterprises: The impacts of country risk, cultural distance and their interactions. Frontiers of Business Research in China, 5(1), 63-78.

Yeh, T.-M., \& Huang, Y.-L. (2014). Factors in determining wind farm location: Integrating GQM, fuzzy DEMATEL, and ANP. Renewable Energy, 66, 159-169.

Yu, C. S. (2002). A GP-AHP method for solving group decision-making fuzzy AHP problems. Computers and Operations Research, 29(14), 1969-2001.

Zhou, J.-L., Bai, Z.-H., \& Sun, Z.-Y. (2014). A hybrid approach for safety assessment in high-risk hydropower-constructionproject work systems. Safety Science, 64, 163-172.

Zhou, Q., Huang, W., \& Zhang, Y. (2011). Identifying critical success factors in emergency management using a fuzzy DEMATEL method. Safety Science, 49(2), 243-252.

Zhou, T. (2013). An empirical examination of continuance intention of mobile payment services. Decision Support Systems, 54(2), 1085-1091.

Publisher's Note

Springer Nature remains neutral with regard to jurisdictional claims in published maps and institutional affiliations.

Submit your manuscript to a SpringerOpen ${ }^{\circ}$ journal and benefit from:

- Convenient online submission

- Rigorous peer review

- Open access: articles freely available online

- High visibility within the field

- Retaining the copyright to your article

Submit your next manuscript at $>$ springeropen.com 